\title{
INTEGRATED ABC/VEN-ANALYSIS OF DRUG PRESCRIPTIONS IN PHARMACOTHERAPEUTIC SCHEMES FOR RELIEF OF DRUNKEN FORMS OF ALCOHOL DEPENDENCE
}

Yurii Chuiev ${ }^{1}$ (PhD in Medical Sciences, Associate Professor), Viktoriia Shapovalova ${ }^{2}$ (Doctor of Pharmaceutical Sciences, Professor)

${ }^{1}$ Medical Center "Avicenna", Kharkiv, Ukraine

${ }^{2}$ Kharkiv Medical Academy of Postgraduate Education, Kharkiv, Ukraine

*Corresponding author: Yurii Chuiev
Received: December 16, 2021

Published: January 25, 2022
Abstract. An integrated ABC/VEN analysis of drug prescriptions in pharmacotherapeutic schemes for the relief of alcoholic dependence was performed. A retrospective analysis of seventy-five anonymized case histories of patients who sought medical help with drunken forms of alcoholic dependence was processed. The scheme of basic pharmacotherapy of relief of drunken forms of alcoholic dependence, developed by associate professor Yurii Chuiev for carrying out interdisciplinary study was used. Substantiated that the introduction of the developed innovative treatment algorithm, with the use of laser therapy, infusion therapy, anticonvulsants and hepatoprotectors allowed to create an effective treatment complex to alleviate this drug pathology. Pharmacoeconomic research was based on organizational and legal, clinical and pharmacological standards. Dosage forms of drugs according to medicinal purposes have been established in pharmacotherapeutic regimens for the relief of drunken forms of alcoholic dependence (tablets occupy $23.1 \%$ of appointments, solutions $-76.9 \%)$. The results of $\mathrm{ABC}$ analysis were given. Category A included seven INNs of drugs, the share of which was $81.13 \%$ of the total cost of pharmacotherapy of alcoholic dependence. Category B included four INNs of drugs with a cost share of $15.07 \%$. In the category of C two INNs of drugs with a share of costs of $4.80 \%$ for pharmacotherapy of relief of drunken states of alcoholic dependence. Overall, $85 \%$ of the studied drugs were included in pharmacotherapy as Vital, $15 \%$ as Essential. The results of the study can be used in conducting of budget tenders for the purchase of drugs, the rational use of drugs, the inclusion of drugs in regional and local forms for pharmacotherapy for the relief of drunken forms of drugs in healthcare facilities.

Keywords: psychoactive substances, alcohol dependence, pharmacotherapy, pharmacoeconomics, $\mathrm{ABC} / \mathrm{VEN}$ analysis, drugs.

Introduction. COVID-19 has led to an unprecedented pandemic that has affected deaths worldwide. In the context of the COVID-19 pandemic, timely pharmacotherapy to alleviate the intoxication of alcohol dependence (AD) will significantly improve the condition and quality of life of such a group of patients. 
Despite numerous publications on COVID-19, the conceptual understanding of the problem is still in its infancy. New public health data in the UK suggest that vaccination against COVID-19 has a positive effect in preventing symptomatic disorders among most patients with comorbidities compared to the rest of the population [1-5].

Pharmacotherapy of patients with intoxicated forms of $\mathrm{AD}$ is one of the most pressing issues of medical care during the COVID-19 pandemic. About 50\% of patients with $\mathrm{AD}$ and coronavirus disease in the postpartum period suffer from withdrawal syndrome. Some foreign authors point to the need to integrate prescriptions into pharmacotherapeutic regimens for the relief of intoxicated forms of $\mathrm{AD}$ into an expanded rehabilitation program, supporting lifestyle changes. White fever, which occurs 2-3 days after withdrawal, is characterized by severe tremor, hallucinations and confusion, leading to death in $4 \%$ of hospitalized patients. Therefore, for such conditions it is necessary to use emergency medical care [6].

Today it is important to use modern, effective and safe drugs for pharmacotherapeutic schemes to relief drunken forms of AD. Further analysis of COVID-19 among patients with AD is important. Pharmacoeconomic methods of analysis, in particular $\mathrm{ABC} / \mathrm{VEN}$ analysis, are used to select effective, safe and affordable drugs [7-9].

For effective relief of the intoxicating form of $\mathrm{AD}$, associate professor Yurii Chuiev developed a basic scheme of pharmacotherapy of AD (thirteen drugs) with the additional use of laser detoxification program, which expanded the possibilities of etiopathogenetic pharmacotherapy. Introduction into the basic (traditional) detoxification program of pharmacotherapeutic drugs of infusion action, having antishock, detoxifying effects, ability to improve microcirculation, arterial and venous circulation, restoration of water-electrolyte balance, the use of anticonvulsants, cancellation, inclusion of hepatoprotective drugs capable of activating enzymes that metabolize ethanol, accelerate the oxidation and elimination of ethanol and acetaldehyde, prevent the occurrence of primary structural degeneration of hepatocytes, drugs enterosorption and sedative formative therapy harmful effects. The study showed that the most significant therapeutic effects of a particular 
pharmacotherapeutic complex was anxiolytic, antiasthenic, hypnotic, antigastric, antiarrhythmic, which are most important in the relief of drunken states of $\mathrm{AD}$ [10].

Subsequently, an interdisciplinary pharmacoeconomic study of pharmacotherapeutic schemes for the relief of drunken forms of $\mathrm{AD}$ on the basis of experimental clinical and pharmacological, organizational, legal and marketing studies was conducted [11]. Thirteen international non-proprietary names (INN) of drugs of Ukrainian (92.3\%) and foreign (7.7\%) manufacturers were selected by medical prescriptions. Found that in pharmacotherapy relief of drunken forms of AD tablets occupy $23.1 \%$ of prescriptions, solutions $-76.9 \%$. The scheme of pharmacotherapy in the relief of drunken forms of AD included $38.5 \%$ of drugs' INNs with ATC classification code "A" - drugs that affect the digestive system and metabolism; 30.7\% with ATC code "B" - drugs that affect the blood system and hematopoiesis; 15.4\% with ATC code "C" - drugs that affect the cardiovascular system and "N" - drugs that affect the nervous system [12]. Nomenclature and legal analysis showed that $92.3 \%$ of the studied drugs have a prescription nomenclature and legal feature. The share of OTC drugs is $7.69 \%$ (INN Antral).

The purpose of the research was to study the pharmacoeconomic indicators of drug availability in the proposed scheme of relief of drunken states of $\mathrm{AD}$ according to the results of $\mathrm{ABC} / \mathrm{VEN}$-analysis.

Materials and methods. The methodological basis of the integrated pharmacoeconomic study of pharmacotherapy of relief of drunken forms of AD was based on organizational and legal, clinical and pharmacological standards: International Classification of Diseases of the $10^{\text {th }}$ edition; International Classification of Diseases of the $11^{\text {th }}$ edition; International Classification of Primary Health Care-2; international and national medical and technological documents on standardization of medical care at $\mathrm{AD}$; normative documents (standards of medical care, clinical protocols, forms of medicines, National list of essential medicines, instructions for medical use); medicines of twelve clinical and pharmacological groups according to ATC codes (A05BA; A11DA01; A11NA02; A11GA01; B03BA0; B05HA05; 
B05BB04; B05CX01; C01EB; C03CA01; N03AF01; N05BA), scientific publications on the topic of the work [13-27].

Integrated experimental studies were conducted at the "Avicenna" Medical Center by the Associate Professor Yurii Chuiev and at the Department of Medical and Pharmaceutical Law, General and Clinical Pharmacy of the Kharkiv Medical Academy of Postgraduate Education by the Professor Viktoriia Shapovalova.

Modern schemes of pharmacotherapy to relief of drunken forms of $\mathrm{AD}$ were processed in the work. The instructions for medical use of drugs were systematized, which allowed to continue the analysis of INNs of essential drugs. More than fifty legislative, normative and legal, instructive and methodical documents for detection and analysis of drugs' INNs used in pharmacotherapy in the relief of drunken forms of $\mathrm{AD}$ were processed. A retrospective analysis of archival data of seventy-five anonymized case histories of patients (2018-2021) who were hospitalized with drunken forms of $\mathrm{AD}$ was conducted. Methods of pharmacoeconomic, clinical and pharmacological, normative and legal, retrospective, documentary, comparative, $\mathrm{ABC} / \mathrm{VEN}$, system and graphic analysis were used [28-33].

The research of the article is a fragment of research work of Kharkiv Medical Academy of Postgraduate Education on "Improving the organizational and legal procedure for providing patients with drugs from the position of forensic pharmacy, organization and management of pharmacy" (state registration number of Ukraine No. 0116U003137, terms 2016-2020), Pharmaceutical and medical law: integrated approaches to the system of drug circulation from the position of forensic pharmacy, organization and management of pharmacy" (state registration number of Ukraine No. 0121U000031, terms 2021-2026).

Results and their discussion. The design of the research on the methodology of integrated pharmacoeconomic research developed at the Department of Medical and Pharmaceutical Law, General and Clinical Pharmacy of Kharkiv Medical Academy of Postgraduate Education was proposed (Table 1). 
Table 1. Design of integrated pharmacoeconomic research.

\begin{tabular}{|c|l|}
\hline $\begin{array}{c}\text { Stages of } \\
\text { the study }\end{array}$ & \multicolumn{1}{c|}{ Content of the study } \\
\hline 1. & Offer of a basic scheme of pharmacotherapy of intoxicating form of AD \\
\hline 2. & $\begin{array}{l}\text { Pharmacoeconomic experiment. ABC-analysis classification by price } \\
\text { from the directory of drugs Compendium. The classification is based on } \\
\text { the Pareto principle }\end{array}$ \\
\hline 3. & $\begin{array}{l}\text { Pharmacoeconomic experiment. VEN-analysis (Vital, Essential, Non- } \\
\text { essential) - directive segmentation of the "necessity" of the range of } \\
\text { drugs. The analysis is based on the regulatory framework }\end{array}$ \\
\hline 4. & $\begin{array}{l}\text { Description and evaluation of the obtained data, formulation of } \\
\text { conclusions, proposals and recommendations }\end{array}$ \\
\hline
\end{tabular}

The proposed scheme of basic pharmacotherapy of the intoxicating form of $\mathrm{AD}$ included thirteen drugs (Table 2).

Table 2. Scheme of basic therapy for the relief of alcohol dependence.

\begin{tabular}{|c|l|l|}
\hline No. & \multicolumn{1}{|c|}{ INN } & \multicolumn{1}{|c|}{ Dosage form } \\
\hline 1. & Antral & Tablets \\
\hline 2. & Ascorbic acid (Vitamin C) & Solution \\
\hline 3. & Carbamazepine & Tablets \\
\hline 4. & Cyanocobalamin (Vitamin B12) & Solution \\
\hline 5. & Electrolytes in combination with other drugs & Solution \\
\hline 6. & Furosemide & Solution \\
\hline 7. & Glucosum & Solution \\
\hline 8. & Hydazepam & Tablets \\
\hline 9. & Inosine & Solution \\
\hline 10. & Magnesium sulfate & Solution \\
\hline 11. & Pyridoxine (Vitamin B6) & Solution \\
\hline 12. & Thiamine (Vitamin B1) & Solution \\
\hline 13. & Phosphatidylcholine from Owl Beans & Solution \\
\hline
\end{tabular}


According to the results presented in the Table 2 it was established that according to the prescription in pharmacotherapy relief of drunken forms of AD tablets occupy $23.1 \%$ of prescriptions made by doctors, solutions $-76.9 \%$.

The next stage of research was the conduct pharmacoeconomic research using $\mathrm{ABC} / \mathrm{VEN}$-analysis, which involves the distribution of drugs by cost of pharmacotherapy and evaluation of the effectiveness of drugs in a healthcare facility (Tables 3, 4).

Table 3. ABC-analysis of drugs for pharmacotherapy relief of drunk forms of alcoholic dependence.

\begin{tabular}{|l|l|c|c|c|}
\hline No. & \multicolumn{1}{|c|}{ INN } & $\begin{array}{c}\text { Costs, } \\
\text { UAH }\end{array}$ & $\begin{array}{c}\text { Share } \\
(\mathbf{\%})\end{array}$ & $\begin{array}{c}\text { ABC } \\
\text { category }\end{array}$ \\
\hline 1. & Pyridoxine (Vitamine B6) & 38,50 & 4,84 & A \\
\hline 2. & Furosemide & 76,30 & 9,58 & A \\
\hline 3. & Hydazepam & 95,20 & 11,96 & A \\
\hline 4. & $\begin{array}{l}\text { Electrolytes in combination } \\
\text { with other drugs }\end{array}$ & 118,50 & 14,89 & A \\
\hline 5. & $\begin{array}{l}\text { Phosphatidylcholine from } \\
\text { Owl Beans }\end{array}$ & 130,20 & 16,35 & A \\
\hline 6. & Antral & 152,20 & 19,12 & A \\
\hline 7. & Thiamine (Vitamin B1) & 27,00 & 3,39 & \\
\hline & Total by category A & $\mathbf{6 3 7 , 9 0}$ & $\mathbf{8 0 , 1 3}$ & \\
\hline 8. & Carbamazepine & 28,20 & 3,54 & B \\
\hline 9. & Inosine & 28,90 & 3,63 & B \\
\hline 10. & Cyanocobalamin & 29,90 & 3,76 & B \\
\hline 11. & Magnesium sulfate & 33,00 & 4,15 & B \\
\hline & Total by category B & $\mathbf{1 2 0}$ & $\mathbf{1 5 , 0 7}$ & \\
\hline & Total by categories AB & $\mathbf{7 5 7 , 9}$ & $\mathbf{9 5 , 2 0}$ & \\
\hline 12. & Glucosum & 15,40 & 1,93 & C \\
\hline 13. & Ascorbic acid (Vitamin C) & 22,80 & 2,86 & C \\
\hline & Total by category C & $\mathbf{3 8 , 2}$ & $\mathbf{4 , 8 0}$ & \\
\hline & Total by categories ABC & $\mathbf{7 9 6 , 1}$ & $\mathbf{1 0 0 , 0 0}$ & \\
\hline & & & & \\
\hline
\end{tabular}


According to the results of $\mathrm{ABC}$-analysis, category A included drugs, the use of which was $81.13 \%$ of the total rate of use; to category $\mathrm{B}-15.07 \%$, and to category $\mathrm{C}$ $-4.80 \%$. Category A includes seven INNs of drugs (Pyridoxine (Vitamin B6), Furosemide, Hydazepam, Electrolytes in combination with other drugs, Phosphatidylcholine from Owl Beans, Antral, Thiamine), the cost of which was 637.9 UAH, which was $81.13 \%$ of the total cost of treatment of the patient. Category B included four INNs of drugs (Carbamazepine, Inosine, Cyanocobalamin, Magnesium sulfate) whose total cost was $120 \mathrm{UAH}(15.07 \%)$. In the category $\mathrm{C}$ there were two INNs of drugs (Glucosum, Ascorbic acid) with cost of 38.2 UAH (4.80\%).

Table 4. VEN-analysis of drugs for pharmacotherapy relief of alcoholic dependence.

\begin{tabular}{|c|c|c|}
\hline No. & Trade name & VEN category \\
\hline 1. & Magnesium sulfate & $\mathrm{V}$ \\
\hline 2. & Thiamine (Vitamine B1) & V \\
\hline 3. & Cyanocobalamin & V \\
\hline 4. & Pyridoxine (Vitamine B6) & $\mathrm{V}$ \\
\hline 5. & Ascorbic acid (Vitamine C) & V \\
\hline 6. & Hydazepam & $\mathrm{V}$ \\
\hline 7. & Carbamazepine & $\mathrm{V}$ \\
\hline 8. & Furosemide & V \\
\hline 9. & Electrolytes in combination with other drugs & V \\
\hline 10. & Inosine & $\mathrm{V}$ \\
\hline 11. & Glucosum & $\mathrm{V}$ \\
\hline 12. & Antral & E \\
\hline 13. & Phosphatidylcholine from Owl Beans & $\mathrm{E}$ \\
\hline
\end{tabular}

According to the results of VEN-analysis found that eleven INNs of drugs (Magnesium sulfate, Thiamine (Vitamin B1), Cyanocobalamin, Pyridoxine (Vitamin B6), Ascorbic acid (Vitamin C), Hydazepam, Carbamazepine, Furosemide, 
Electrolytes in combination with other drugs, Inosine, Glucosum) belong to category V (Vital). Category E (Essential) included two INNs of drugs (Antral, Phosphatidylcholine from Owl Beans). Category N (Non-essential) did not include any drugs.

The distribution according to the results of VEN-analysis of the studied INNs of drugs for pharmacotherapy of relief of drunken forms of AD shown on the Fig. 1.

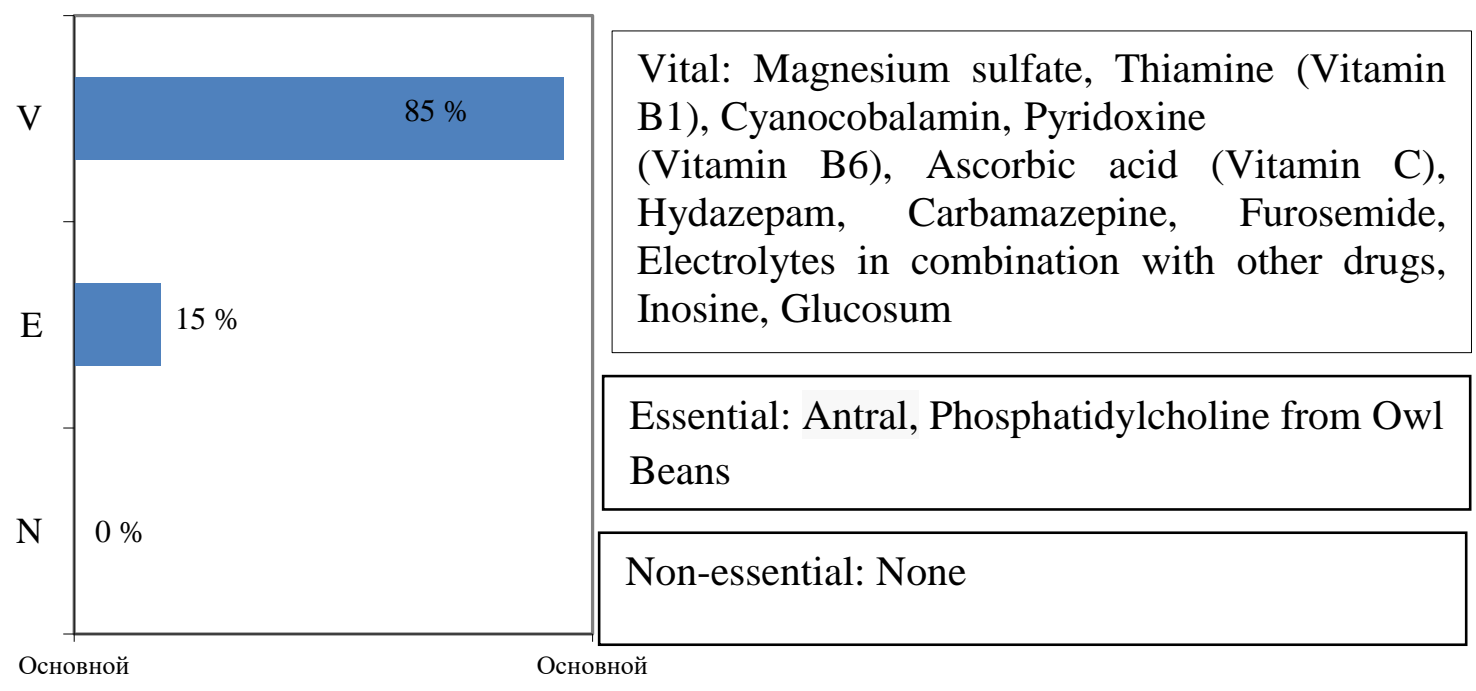

Fig. 1. Distribution in accordance with the results of VEN-analysis of the studied drugs for pharmacotherapy of alcohol dependence.

The studied drugs in their 85\% (Magnesium sulfate, Thiamine (Vitamin B1), Cyanocobalamin, Pyridoxine (Vitamin B6), Ascorbic acid (Vitamin C), Hydazepam, Carbamazepine, Furosemide, Electrolytes in combination with other drugs, Inosine, Glucosum) include in the pharmacotherapy as vital (V category), in 15\% (Antral, Phosphatidylcholine from Owl Beans) as essential (E category).

Based on the conducted ABC/VEN analysis, a matrix of the consolidated $\mathrm{ABC} / \mathrm{VEN}$ analysis was developed (Table 5).

Studies show the following: INNs of drugs in category $\mathrm{V}$ accounted for the most costs $64.53 \%$, in category $\mathrm{E}-35.47 \%$, in category $\mathrm{N}$ - no costs. The share of expenditures accounted for by drugs: by categories: A/V (44.47\%) - the highest indicator of the total rate of prescription drugs; for $\mathrm{A} / \mathrm{E}-35.47 \%$ and $\mathrm{A} / \mathrm{N}-0 \%$. By 

category $\mathrm{B} / \mathrm{V}-15.07 \%$; by category $\mathrm{B} / \mathrm{E}-0 \%$ and $\mathrm{B} / \mathrm{N}-0 \%$. Drugs in category $\mathrm{C}$ had the corresponding indicators: $\mathrm{C} / \mathrm{V}-4.80 \% ; \mathrm{C} / \mathrm{E}-0 \% ; \mathrm{C} / \mathrm{N}-0 \%$.

Table 5. Matrix of the consolidated ABC-VEN-analysis of drugs for pharmacotherapy of relief of drunken forms of alcoholic dependence.

\begin{tabular}{|c|c|c|c|c|c|c|c|c|c|}
\hline \multirow{2}{*}{ 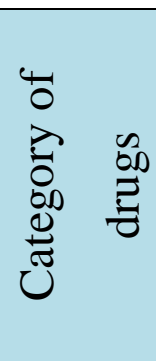 } & \multirow{2}{*}{ 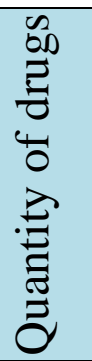 } & $\begin{array}{l}\text { Prescri } \\
\text { drugs }\end{array}$ & tion of & \multirow{2}{*}{ 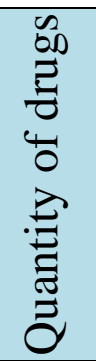 } & \multicolumn{2}{|c|}{\begin{tabular}{l}
\multicolumn{1}{c}{$\mathbf{E}$} \\
Prescription of \\
drugs
\end{tabular}} & \multirow{2}{*}{ 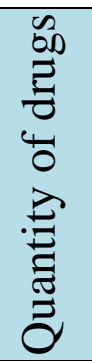 } & \multicolumn{2}{|c|}{\begin{tabular}{l}
\multicolumn{1}{c}{$\mathbf{c}$} \\
Prescription \\
of drugs
\end{tabular}} \\
\hline & & UAH & $\%$ & & UAH & $\%$ & & UAH & $\%$ \\
\hline $\mathbf{A}$ & 5 & 355,5 & 44,47 & 2 & 282,4 & 35,47 & - & - & - \\
\hline B & 4 & 120 & 15,07 & - & - & - & - & - & - \\
\hline C & 2 & 38,2 & 4,80 & - & - & - & - & - & - \\
\hline Total: & 11 & 513,7 & 64,53 & 2 & 282,4 & 35,47 & - & - & - \\
\hline
\end{tabular}

The results of the study can be used in conducting budget tenders for the purchase of drugs, the rational use of drugs, the inclusion of drugs in regional and local forms for pharmacotherapy for the relief of drunken forms of drugs in health care facilities.

Conclusions. An integrated $\mathrm{ABC} / \mathrm{VEN}$ analysis of drug prescriptions in pharmacotherapeutic schemes for the relief of drunken forms of $\mathrm{AD}$ was performed. Used developed by Associate Professor Yurii Chuiev scheme of basic pharmacotherapy of relief of drunken forms of AD for interdisciplinary study. Dosage forms of drugs according to medicinal purposes in pharmacotherapeutic schemes of relief of drunken forms of $\mathrm{AD}$ were established. The results of $\mathrm{ABC}$ analysis were given. Category A included seven INNs of drugs, the cost of which was $81.13 \%$ of the total cost of pharmacotherapy of patients. Total of $85 \%$ of the studied drugs were included in pharmacotherapy as vital (V category), $15 \%$ as essential (E category). The matrix of the consolidated $\mathrm{ABC} / \mathrm{VEN}$-analysis of drugs for pharmacotherapy of relief of drunken forms of AD showed that INNs of drugs in the Vital category account for 
the highest costs of $64.53 \%$, in the Essential category - 35.47\%, in the Non-Essential category - no costs.

Further research on pharmacoeconomic indicators of drug availability in the proposed pharmacotherapy schemes are ongoing.

Ethical approval. Ethical clearance was obtained from the administration of "Avicenna" Medical Center and Kharkiv Medical Academy of Postgraduate Education. A permission statement for conducting the experiments was received from the administration of "Avicenna" Medical Center. Before any data collection, the main purpose of the study was clearly explained to each department (concerned personnel).

Conflict of interests. The authors declare that they have no conflict of interests or/and competing interests.

Funding. The authors state, that there was no funding from any agencies for this study.

\section{References.}

1. Roberts M. Covid-19: New mutation of Delta variant under close watch in UK. BBC News online. 19.10.2021. URL: https://www.bbc.com/news/health-58965650.

2. Clive Cookson C., Burn-Murdoch J. New Delta descendant may be more infectious than its ancestor. FT. 18.10.2021. URL: https://www.ft.com/content/f1ec9d5d-9e02-4cc4-95e7-1dcbb1844d43.

3. Dr Fauci on Delta variant: Unvaccinated Americans risk new Covid surge. $B B C$. 2021. URL: https://www.bbc.com/news/av/world-us-canada-57576697.

4. COVID-19 dashboard by the Centre for Systems Science and Engineering at John Hopkins University (2021). COVID-19 dashboard by the Centre for Systems Science and Engineering at John Hopkins University. URL: https://coronavirus.jhu.edu/map.html.

5. Shapovalova V.O., Zbrozhek S.I., Shapovalov V.V. et al. Coronavirus disease pandemia 2019: growth of epidemic dangers. Acta scientific pharmaceutical sciences. 2020. Vol. 4. Issue 7. P. 61-68. URL: https://doi.org/10.31080/ASPS.2020.04.0559. 
6. Day E., Daly C. Clinical Management of the Alcohol Withdrawal Syndrome. Addiction. 2021. URL: https://doi.org/10.1111/add.15647.

7. Health Care for All: A Framework for Moving to a Primary Care-Based Health Care System in the United States. AAFP. 19.10.2021. URL: https://www.aafp.org/about/policies/all/health-care-for-all.html.

8. Fact Sheet: The American Rescue Plan: Reduces Health Care Costs, Expands Access to Insurance Coverage and Addresses Health Care Disparities. HHS.gov. 12.05.2021. URL: https://www.hhs.gov/about/news/2021/03/12/fact-sheet-american$\underline{\text { rescue-plan-reduces-health-care-costs-expands-access-insurance-coverage.html. }}$

9. CMS Completes Historic Price Transparency Initiative. CMS.gov. 29.10.2020.

URL: https://www.cms.gov/newsroom/press-releases/cms-completes-historic-pricetransparency-initiative.

10. Chuiev Yu. Modern possibilities of application of detoxification laser programs when mitigating drinking forms of alcoholization. SSP Modern Pharmacy and Medicine. 2021. Vol. 1. No. 1. P. 1-14. URL: https://doi.org/10.53933/sspmpm.v1i1.6. 11. Chuiev Y., Shapovalova V. Interdisciplinary pharmacoeconomic study of pharmacotherapy of cupping of drunk forms of alcohol dependence: clinical and pharmacological, organizational, legal and marketing experiment. SSP Modern Pharmacy and Medicine. 2021. Vol. 1. No. 2. P. 1-12. https://doi.org/10.53933/sspmpm.v1i2.24.
12. ATC-classification.
Compendium
on-line.
2020.
URL:

http://compendium.com.ua/atc.

13. International Statistical Classification of Diseases and Related Health Problems (ICD). World Health Organization. URL: http://www.who.int/classifications/icd/en/. 14. The International Statistical Classification of Diseases and Related Health Problems, Tenth Revision, Australian Modification (ICD-10-AM). URL: https://www.ihpa.gov.au/what-we-do/icd-10-am-achi-acs-current-edition.

15. Concerning the statement of clinical protocols of rendering of medical care in a specialty "Narcology". Order of the Ministry of Health of Ukraine No. 681 dated 21 Septrember, 2009. URL: http://medstandart.net/byspec/49. 
16. Order of the Ministry of Health of Ukraine. On approval of the twelfth issue of the State formulary of medicines and ensuring its availability. Ministry of Health of Ukraine. Dated 06.05.2020 N. 1075. URL: https://zakon.rada.gov.ua.

17. National list of basic medicines. (2009). Resolution of the Cabinet of Ministers of Ukraine of 25.03.2009 No. 333. URL: http://zakon.rada.gov.ua.

18. Shapovalova V.A., Zbrozhek S.I., Shapovalov V.V. et al. Forensic pharmacy: some risk factors in the formation of addictive health disorders. Acta Scientific Pharmaceutical Sciences. 2021. $\quad$ V. $4 . \quad$ Iss. $1 . \quad$ P. 7 12. $\quad$ DOI: 10.3180/ASPS.2020.05.0651.

19. Gudzenko A., Shapovalov V., Shapovalova V. et al. Organization and legal aspects of the use of marketing analysis of multivitamin complexes for pharmaceutical provision of health diseases among combatants. Acta scientific pharmaceutical sciences. 2021. V. 5. Iss. 4. P. 74 80. DOI: 10.31080/ASPS.2021.05.0704.

20. Gudzenko A., Shapovalov V., Shapovalov V. et al. Forensic pharmacy: analysis of complaints about the pharmaceutical provision for privileged categories of patients in Ukraine (experimental research). Science Review. 2021. V. 2. Iss. 37. P. 1 6. URL: https://doi.org/10.31435/rsglbal_sr/30042021/7517.

21. Hayduchok I.G., Shapovalova V.O., Ishcheikin K.E. et al. Pharmaeconomic approaches for pharmacotherapy of Rheumatoid arthritis. Likars'ka Sprava. 2021. N. 1-2. P. 54-63. DOI: 10.31640/JVD.1-2.2021(8).

22. Shapovalov V. (Jr.), Gudzenko A., Komar L.et al. Concerning the importance of forensic and pharmaceutical researches to improve patients' accessibility to medicines. Pharmacia. 2017. Vol. 65. N. 2. P. 23-29.

23. Shapovalov V. (Jr.), Gudzenko A., Shapovalova V. et al. Forensic and pharmaceutical study of the presence of a causal link between the degree of alcohol abuse and qualification level of the respondents. Pharmacia. 2017. Vol. 66. N. 3. P. 31-39. URL: http://bsphs.org/wp-content/uploads/2017/11/Shapovalov.pdf.

24. Shapovalov V. (Jr.), Zbrozhek S., Gudzenko A.et al. Organizational and legal analysis of the pharmaceutical provision for the most common diseases of society. International Journal of Pharmaceutical Sciences Review and Research. 2018. Vol. 
51. N. 1. P. 118-124. URL: http://globalresearchonline.net/journalcontents/v511/18.pdf.

25. Shapovalov V.V. (Jr.), Zbrozhek S.I., Shapovalova V.O. et al. Organizational and legal evaluation of availability of medicines' circulation for cancer patients. Pharmacia. 2018. Vol. 65. N. 2. P. 17-22. URL: http://bsphs.org/?magasine=organizational-and-legal-evaluation-of-availability-ofmedicines-circulation-for-cancer-patients.

26. Shapovalova V.A., Shapovalov V.V., Shapovalov V.V. et al. Forensic and pharmaceutical assessment of polydrug addiction at combined use of psychoactive substance. Likars'ka sprava. 2018. N. 1-2 (1146). P. 171-177. URL: https://doi.org/10.31640/JVD.1-2.2018(29).

27. Forensic and pharmaceutical analysis of addictive morbidity because of the use of narcotic psychoactive substances in Ukraine (retrospective aspect) / V. Shapovalov (jr.), A. Gudzenko, V. Shapovalova, V. Shapovalov. International Journal of Pharmaceutical Sciences and Research. 2018. Vol. 3; Is. 3; July 2018; P. 22-25. URL: http://www.pharmacyjournal.net/archives/2018/vol3/issue3.

28. Health Care for All: A Framework for Moving to a Primary Care-Based Health Care System in the United States. AAFP. 19.10.2021. URL: https://www.aafp.org/about/policies/all/health-care-for-all.html.

29. Snow J. United States Agency for International Development. Logistics Indicators Assessment Tool. 2005. Arlington, VA.: J. Snow, Inc. Deliver. 278 p.

30. Management Science for Health. Managing Medicines Selection. 2012. Managing Access to Medicines and Health Technologies (16.1-16.15). Arlington, VA, USA: MSH.

31. Mamarde A. ABC/VEN Analysis of drug store in Tertiary care hospital for year 2013-2014. American Journal of Pharmaceutical Research. 2016. Vol. 6. N. 8. P. 6439-6444.

32. CMS Completes Historic Price Transparency Initiative. CMS.gov. 29.10.2020. URL: https://www.cms.gov/newsroom/press-releases/cms-completes-historic-pricetransparency-initiative. 
SSP Modern Pharmacy and Medicine (ISSN 2733-368X), Volume 2 Issue 1, Jan-Mar 2022

33. Fact Sheet: The American Rescue Plan: Reduces Health Care Costs, Expands Access to Insurance Coverage and Addresses Health Care Disparities. HHS.gov. 12.05.2021. URL: https://www.hhs.gov/about/news/2021/03/12/fact-sheet-american$\underline{\text { rescue-plan-reduces-health-care-costs-expands-access-insurance-coverage.html. }}$ 